\title{
Residência Multiprofissional em Saúde e Formação de Psicólogos para o SUS
}

\author{
Isabel Sampaio dos Santos Ferreira ${ }^{1}$ \\ ${ }^{1}$ Universidade Federal do Rio de Janeiro, RJ, Brasil.
}

\author{
Cecília Teixeira Soares ${ }^{1}$ \\ ${ }^{1}$ Universidade Federal do Rio de Janeiro, RJ, Brasil.
}

\begin{abstract}
Resumo: A inserção da psicologia na área da saúde ocorreu de modo convencional, sem que houvesse adaptação aos novos contextos de atuação. Concomitantemente, a graduação em Psicologia está ainda muito ancorada na área clínica, com poucas discussões sobre outras possibilidades de atuação. Partindo da inserção da psicologia em programas de residência multiprofissional em saúde, buscou-se compreender a percepção do psicólogo residente quanto à contribuição de seu saber para as equipes multiprofissionais e do efeito da vivência da residência para sua formação profissional. A coleta de dados partiu da realização de grupos focais e empregou-se a análise de conteúdo para seu tratamento. Além disso, considerou-se os sentimentos e experiências da pesquisadora, acentuando sua implicação no processo de pesquisa e desmistificando uma suposta neutralidade científica. Os resultados da pesquisa apontam que o amparo institucional da residência se coloca tanto como uma expectativa segura após a graduação, quanto como um desafio para a atuação do psicólogo, assim como evidenciam lacunas e contribuições na graduação em psicologia e indicam a necessidade de maior inclusão de temáticas de grupo, saúde e gênero nas grades curriculares. Além disso, a pesquisa registra as frustrações do residente ao lidar com o contexto atual de sucateamento do Sistema Único de Saúde; a importância do trabalho multiprofissional para garantir atenção integral em saúde; e os aprendizados que fazem da passagem pela residência um divisor de águas. Todos esses achados permitem afirmar que espaços como a residência multiprofissional em saúde constituem campos teórico-práticos de amadurecimento profissional do psicólogo profissional de saúde.
\end{abstract}

Palavras-chave: Sistema Único de Saúde, Psicologia, Formação Profissional.

\section{Multiprofessional Residency in Health and Training of Psychologists for the SUS}

\begin{abstract}
The insertion of Psychology in the Health System has traditionally occurred without the adaptation to new contexts of professional action. At the same time, the degree in Psychology is still predominantly anchored in the clinical area, with few discussions on other areas. Based on the theme of the insertion of Psychology into Multiprofessional Residency Programs in Health, this study aimed to understand the resident psychologists' perception of the contribution of their own knowledge in the performance of multiprofessional teams and the effect of living the residence for professional training. The research counted on the meeting of focal groups, and with the method of Content Analysis to treat the data collected. Moreover, the feelings and experiences of the researcher were considered to accentuate their implication in the research process, demystifying a supposed scientific neutrality. The results of the research point out, among others, that the institutional protection of the residence represents a safe expectation after graduation, as a challenge for action; gaps and contributions in the course of Psychology; and the need for greater inclusion of grouping, health and gender themes in the curriculum; frustrations of the resident in dealing with the current context of the scrapping of the Brazilian Unified Health System; the importance of multiprofessional work to guarantee integral health care; and learnings that make the passage through the residence a watershed. All of this allows to
\end{abstract}


affirm the Multiprofessional Residency in Health as a theoretical-practical field of professional maturation as a professional health psychologist.

Keywords: Unified Health System, Psychology, Vocational Training.

\title{
Residencia Multiprofesional en Salud y Formación de Psicólogos para el SUS
}

\begin{abstract}
Resumen: La inserción de la Psicología en el campo salud se dio tradicionalmente sin que hubiera adaptación a los nuevos contextos de actuación. Al mismo tiempo, la graduación en Psicología se ve todavía predominantemente anclada en el área clínica y con pocas discusiones sobre otros ámbitos. A partir de la inserción de la Psicología en programas de residencia multiprofesional en salud, se pretendió comprender la percepción del psicólogo residente en cuanto a la contribución de su saber en la actuación en equipos multiprofesionales y del efecto de la vivencia en la residencia para su formación profesional. Los datos recopilados derivaron de la realización de grupos focales, y para analizarlos se utilizó el método del análisis de contenido. Además, los sentimientos y experiencias de la investigadora se consideraron a fin de acentuar su implicación en el proceso de investigación, desmitificando una supuesta neutralidad científica. Los resultados de la encuesta apuntan que el amparo institucional de la residencia se sitúa como una expectativa segura después de la graduación y un desafío para la actuación; evidencian las lagunas y contribuciones en la graduación en Psicología; y muestran la necesidad de una mayor inclusión de temáticas de grupo, salud y género en el currículo académico. Además, la investigación permitió identificar las frustraciones del residente al tratar con el contexto actual de depreciación del Sistema Único de Salud; la importancia del trabajo multiprofesional para garantizar una atención integral en salud; y los aprendizajes que hacen del paso por la residencia un divisor de aguas. Todo ello permite afirmar espacios como de la residencia multiprofesional en salud como campos teórico-prácticos de maduración profesional del psicólogo profesional de salud.
\end{abstract}

Palabras-clave: Sistema Único de Salud, Psicología, Formación Profesional.

\section{Introdução}

A inserção da psicologia na área da saúde, como já aponta a literatura, se deu em geral como uma (quase) transposição e reprodução do modelo clínico dos consultórios particulares para o âmbito dos hospitais e da saúde pública, sem que houvesse uma adaptação a estes novos contextos de atuação (Yamamoto, 2003, citado por Santos, Quintanilha, \& Dalbello-Araujo, 2010). Essa forma de intervenção, com foco nos atendimentos individuais, acaba por não atender às reais demandas encontradas no cotidiano dos serviços públicos de saúde, deixando de lado outras modalidade de atendimentos possíveis, como o trabalho em grupo com usuários ou equipes multiprofissionais e as ações intersetoriais. Para Pires e Braga (2008), é fundamental, portanto, repensar as atuações, teorias e campos práticos para a construção de estratégias de formação em psicologia adaptadas ao contexto concreto do setor saúde.

A própria formação nos cursos de graduação em psicologia costuma não oferecer ao estudante conhecimentos cruciais acerca dos aspectos sociais, ao passo que enfoca demasiadamente as perspectivas individual e intrapsíquica, como se tais dimensões fossem dissociadas. Dessa forma, o currículo se torna, por vezes, limitado e inadequado às realidades socioculturais, sanitárias e políticas (Dimenstein, 2000, citado por Pires \& Braga, 2008). Tudo isso, em conjunto com o desconhecimento de outros meios de atuação e do papel do psicólogo nos serviços de saúde, reforça o modelo clínico clássico. A falta de clareza desse papel pelos próprios psicólogos pode acarretar ainda a dificuldade de comunicação entre diferentes saberes presentes em equipes multiprofissionais, à medida 
que outros profissionais também não compreendem o lugar da psicologia dentro do trabalho coletivo (Tonetto \& Gomes, 2007).

Benevides (2005) lamenta a pouca e ainda incipiente preocupação do campo da psicologia com o viés político do campo da saúde pública e com as atuações profissionais que ultrapassam o enfoque clínico individual. Ancoradas em um paradigma que separa a ciência da política e, portanto, distancia a psicologia das questões políticas que envolvem o Sistema Único de Saúde (SUS), as práticas da psicologia é pautada por uma dicotomia sujeito-sociedade que despolitiza suas atividades e que, muitas vezes, pode limitar o trabalho do profissional. Nesses termos, produz-se outra separação: a micropolítica, representada pelas questões subjetivas e a macropolítica, representada pelo SUS. Segundo a autora, a psicologia atravessada por estas dicotomias torna o cuidado com a saúde das pessoas dissociado de aspectos mais abrangentes, como a saúde das populações.

Tudo isso pode se refletir em hiatos no exercício da profissão do psicólogo inserido em uma residência multiprofissional em saúde (RMS), que precisa lidar com os desafios de um trabalho no qual a troca entre diferentes disciplinas é imprescindível e que se depara com a realidade própria do SUS e das políticas públicas. Neste sentido, esta pesquisa buscou refletir sobre a percepção do residente de psicologia quanto à contribuição de seu saber na atuação em equipes multiprofissionais e do efeito da vivência da residência multiprofissional para sua formação profissional. Além disso, ela buscou identificar quais aspectos da graduação em psicologia funcionaram, na visão dos psicólogos residentes, como facilitadores ou lacunas para sua inserção no Programa de Residência Multiprofissional em Saúde da Mulher do Instituto de Atenção à Saúde São Francisco de Assis (HESFA/UFRJ). Também foram consideradas possíveis diferenças na percepção dos participantes do primeiro ano, segundo ano, e após a conclusão do programa.

Assim, esta pesquisa pretendeu contribuir para o conhecimento sobre a formação do psicólogo, ampliando as possibilidades de atuação ao articular a psicologia com outras disciplinas no trabalho multiprofissional e afirmando que espaços como a RMS constituem campos teórico-práticos de aperfeiçoamento profissional. O estudo também buscou identificar alguns aspectos da graduação em psicologia ao sugerir que algumas pautas precisam ser mais discutidas e, talvez, integradas aos currículos, como os estudos sobre saúde pública, SUS e o trabalho em equipes multiprofissionais. A relevância social da atuação do psicólogo em equipes multiprofissionais se reflete, por fim, na possibilidade dos residentes em saúde oferecer aos usuários dos serviços de saúde um atendimento mais qualificado, com olhar amplo sobre a complexidade de cada queixa, ao considerar cada pessoa como ser total e integral.

\section{A inserção da psicologia na área da saúde: contextualizando (novos) caminhos}

A psicologia se constitui tradicionalmente em um campo de saber centrado em três modelos de atuação: clínica, escolar e organizacional. Apesar da regulamentação da profissão datar de 1962, a inserção do psicólogo na saúde no Brasil teve início já na década de 1950. O processo de inserção da psicologia na saúde pública se deu no final da década de 1970, a princípio para atender a demandas de origem psiquiátrica (Pires \& Braga, 2008). Tendo em vista a reforma psiquiátrica e a perspectiva de construir modelos alternativos ao hospital psiquiátrico, a psicologia passou a estar presente nos serviços públicos de saúde a partir das equipes multiprofissionais (Carvalho \& Yamamoto, 2002, citado por Pires \& Braga, 2008).

A inclusão da psicologia no campo da saúde não pode ser vista de forma dissociada da própria mudança na compreensão do que é saúde. Com o aumento de doenças ligadas a hábitos e ao estilo de vida das pessoas, começou a haver um olhar para aspectos para além dos biológicos que podem influir no adoecimento, passando o contexto sociocultural a ser valorizado como um determinante da saúde. Ao passar a se entender o binômio saúde-doença como um processo difícil de se caracterizar, por ser ele atravessado por uma pluralidade de fatores, as práticas de promoção da saúde e prevenção de doenças foram aos poucos se consolidando como estratégia relevante e necessária na atenção à saúde. Por meio de uma perspectiva ampliada e integral de saúde, o envolvimento de variados profissionais num trabalho coletivo foi ganhando o seu espaço (Pires \& Braga, 2008).

No bojo deste processo, o cenário político no Brasil também influenciou para que se (re)pensasse a própria concepção do que é saúde e do que é fazer saúde. Com a Constituição Federal de 1988, o conceito de saúde, expresso no Art. 196, se torna um direito de todos assim como um dever do Estado, o que incluiu 
as ações de redução do risco de doenças, assim como a promoção, proteção e recuperação da saúde. O conceito de saúde deixou, então, de ser reduzido à ausência de doenças e apenas ao domínio biológico, ampliando sua compreensão para os determinantes de ordens antes não vislumbradas, como a psicológica, social, econômica, cultural e a de direito assegurado por lei. Sobre a superação da compreensão biomédica de saúde, Santos, Quintanilha e DalbelloAraujo (2010) sustentam que as práticas coletivas e a articulação intersetorial possam funcionar como facilitadores na produção de pessoas solidárias e autônomas nas decisões caras à saúde.

Outro ponto que merece destaque se refere aos próprios currículos de graduação em psicologia e as lacunas deixadas na formação. Com o avanço científico-metodológico ao longo das décadas, desde a legislação inicial até o currículo mínimo dos cursos de psicologia, o psicólogo se viu conquistando novos espaços de atuação e reconfigurando sua prática. Por essas razões, surgiu o projeto de resolução que instituiu as Diretrizes Curriculares Nacionais para os Cursos de Graduação em Psicologia (Conselho Nacional de Educação, 2001) que propôs estabelecer princípios curriculares baseados em competências e habilidades profissionais para os cursos de graduação em psicologia. Dentre os princípios e compromissos, alguns se destacam por expandirem a visão tradicional do fazer em psicologia, como a interface dos fenômenos psicológicos com os biológicos e sociais, o olhar crítico para dimensões socioeconômica, política e cultural e o trabalho com promoção de qualidade de vida dos indivíduos, grupos, organizações e comunidades em diversos contextos.

Este documento traz ainda a definição de competências gerais para formação em psicologia que incluem a "atenção à saúde", caracterizando o desenvolvimento de ações de prevenção, promoção, proteção e reabilitação da saúde em nível individual e coletivo. Dentre as competências específicas para o formado em psicologia, está a atuação inter e multiprofissional. Estas ideias podem ser encontradas também na definição dos "eixos estruturantes", presentes no Art. 10 do documento. Os eixos estruturantes que definem os conteúdos curriculares trazem tópicos como a "interface com campos afins do conhecimento", o que demarca a importância do diálogo com outros saberes. O Projeto de Resolução sofreu algumas alterações nos anos seguintes, ao ser acrescentado um item sobre "Psicologia e processos de prevenção e promoção da saúde" (Conselho Nacional de Educação, 2004), o que destaca a importância das ações preventivas individuais e coletivas para proteção e promoção da qualidade de vida.

Tudo isso se traduz em embasamentos nos quais a psicologia pode se apoiar para que sua inserção na saúde esteja de fato engajada com o compromisso ético-político de atuar no SUS. Apesar dos esforços, seja no âmbito da legislação, por meio da bases curriculares, seja nos da teoria ou da prática, a formação em psicologia ainda precisa de muitas outras mudanças a fim de ampliar seu papel na sociedade e, mais especificamente, no campo da saúde. Continuar investindo em capacitação e, mais especificamente, no modelo de uma RMS parece ser um potente caminho a se seguir.

\section{Residências multiprofissionais em saúde: a atuação em equipe multiprofissional}

O histórico das residências em saúde é marcado pela hierarquização do saber médico sobre as demais disciplinas, o que se desdobrava, na prática, na existência de apenas residências médicas no início desse tipo de especialização como formação em serviço. A primeira residência não médica no Brasil data de 1961, quando foi criada a residência em enfermagem pelo Hospital Infantil do Morumbi (SP). Em 1976, surgiu, por meio da Secretaria de Estado da Saúde do Rio Grande do Sul, a primeira residência em medicina comunitária na Unidade Sanitária São José do Murialdo, que pouco depois, em 1978, se transformou na primeira experiência de uma residência multiprofissional (Martins, Caregnato, Barroso, \& Ribas, 2016).

Desde a década de 1970, havia em todo Brasil experiências uni e multiprofissionais de especializações na área da saúde nos moldes de uma residência que iam além da modalidade médica, como as em atenção básica, saúde da família, saúde mental etc. Apesar disso, estas especializações ainda não tinham regulamentação própria que as enquadrasse nos critérios de um programa de residência. Foi apenas em 2005, por meio da Lei no 11.129 (2005), que finalmente instituiu-se, no Art.13, a "Residência em Área Profissional da saúde", modalidade de ensino de pós-graduação lato sensu com duração de dois anos em regime de dedicação exclusiva, destinada à educação em serviço e qualificação de jovens profissionais da saúde. A proposta de integração entre os campos da saúde e da educação visava 
investir num tipo de formação profissional com vistas de retorno aos serviços de saúde, preferencialmente aos que compõem o SUS.

A RMS se consolida então como estratégia pensada a partir do âmbito do SUS, como dispositivo de ensino-serviço para formação e atuação na saúde, de modo que garantia a integralidade do cuidado no atendimento por meio do trabalho em equipe interdisciplinar. Verificando-se o que existe hoje em dia de programas de RMS, constatou-se a presença de uma série de tipos distintos em todo o Brasil, muitos voltados às particularidades de grupos populacionais e contextos de atenção à saúde. Essa pluralidade também aponta para a importância da diversidade de saberes que trabalham juntos a fim de garantir a integralidade no cuidado aos usuários que chegam aos serviços de saúde.

Apesar disso, tais programas ainda precisam solucionar uma série de dificuldades para sua efetiva implementação. Segundo Martins et al. (2016), a falta de conhecimento na graduação sobre a multiprofissionalidade e a integralidade, a baixa integração entre preceptores e tutores e a sobrecarga de trabalho e de função destes profissionais sem que haja acréscimo nos salários ou gratificações são alguns dos principais desafios que atravessam o bom êxito das RMS. Outros agravantes são a ausência ou a desqualificação das preceptorias, as relações pedagógicas marcadas pela sobreposição do saber do especialista e a inadequação da infraestrutura (Ramos et al., 2006). Por estas razões, as instituições que funcionam como espaços teórico e/ou prático das RMS adquirem papel fundamental. Elas devem assumir responsabilidade na formação de profissionais críticos e sensíveis, capacitados para atender às demandas da população em geral nos serviços públicos de saúde (Martins et al., 2016).

Já a Política Nacional de Humanização da Saúde (Secretaria de Atenção à Saúde, 2010) carrega a necessidade de mudanças no modelo de atenção ao mesmo tempo em que o modelo de gestão se transforma. Ela defende os valores de autonomia, do protagonismo dos sujeitos e da corresponsabilidade, a promoção de vínculos solidários e de redes de cooperação, e a participação coletiva na gestão da saúde. Isso implica uma maior comunicação intra e intergrupos, tornando mais leves e flexíveis as linhas que separam sujeito-saber e saberes coletivos, relações de poder e relações de trabalho.

Por fim, juntando os fios das políticas de saúde com os dos conhecimentos e práticas da psicologia,
Benevides (2005) identifica na psicologia o papel político de construção de grupalidades e redes assim como o de cogestão nas ações transversais, sendo, portanto, instrumento da democracia. Tendo em vista que esta pesquisa trata da inserção da psicologia em uma RMS, compreende-se que o trabalho do psicólogo não resulta isolado, mas se enriquece, e é enriquecido, por meio do diálogo e das trocas horizontais entre diferentes disciplinas.

\section{Metodologia}

O presente trabalho consistiu em uma pesquisa de abordagem qualitativa. O campo de estudo adotado foi o Instituto de Atenção à Saúde São Francisco de Assis (HESFA), à medida que nele ocorre o Programa de Residência Multiprofissional em Saúde da Mulher do HESFA/UFRJ. O HESFA é uma das instituições que compõem o Complexo Hospitalar da Universidade Federal do Rio de Janeiro (CHUFRJ), caracterizado por ser uma unidade acadêmica docente-assistencial responsável por atividades de ensino, pesquisa e extensão. Esta residência, por sua vez, inclui residentes das categorias profissionais de psicologia, enfermagem e serviço social que formam equipes (trios) multiprofissionais com um integrante de cada uma dessas áreas do saber.

A coleta de dados aconteceu através de três grupos focais, sendo um deles formado por quatro residentes do primeiro ano (R1), um com três residentes do segundo ano (R2) e outro com três residentes já formados. Este trabalho contou, então, com dez participantes de ambos os sexos. Optou-se pela técnica de grupos focais para se captar a autopercepção, os sentimentos, as dificuldades e as surpresas encontradas e/ou esperadas pelos residentes durante sua inserção na RMS. Segundo Virgínio e Nóbrega (2012), o grupo focal possibilita maior abertura para que o participante fale além do esperado, evitando respostas prontas ou padronizadas à medida que muitas falas se complementam ou mudam de direção a partir da discussão em grupo. É, portanto, um espaço de reflexão crítica e coletiva, de problematizações e debates, de consensos e divergências, de comunicação e troca de vivências.

Além dos participantes, o grupo focal contou com a presença de um moderador que, neste caso, foi a própria pesquisadora, primeira autora do artigo, responsável por disparar questões de debate, conduzir o grupo e estimular a participação dos integrantes 
de forma livre e espontânea. A fim de auxiliar o moderador durante este processo, houve ainda a colaboração de um observador externo que registrou aspectos não verbais dos participantes assim como a dinâmica de comunicação entre os participantes e entre eles e a moderadora no desenrolar do grupo.

A organização dos dados ocorreu por meio da transcrição do material gravado para fins da pesquisa. A pesquisadora cuidou para assegurar a privacidade e confidencialidade dos participantes e das informações que relataram. O estudo ocorreu após aprovação, com o número 65501017.0.0000.5238, pelo Comitê de Ética em Pesquisa da Escola de Enfermagem Anna Nery e do Instituto de Atenção à Saúde São Francisco de Assis da Universidade Federal do Rio de Janeiro (CEPE/EEAN/Hesfa/UFRJ).

Já a análise dos dados baseou-se na técnica de análise de conteúdo (Bardin, 1977). Bardin propõe a descrição do conteúdo das falas ou textos de forma sistemática e objetiva para que depois se faça as inferências e interpretações. A análise buscou ir para além dos significados aparentes das mensagens, buscando novos sentidos.

Quanto à categorização, destaca-se que não foi necessariamente sua frequência ou prevalência que definiram mais uma categoria, mas o grau de significância atribuído pela pesquisadora a determinado conjunto de dados de acordo com sua representatividade para a pesquisa. Nesse sentido, o julgamento e o papel ativo da pesquisadora ganharam dimensões cruciais no processo da pesquisa. Papel ativo, pois pesquisar implica tomar decisões durante todo seu processo, escolhendo o que priorizar ou desconsiderar à medida que a pesquisa não consegue abarcar toda pluralidade que os dados comportam.

A escolha de tal método se preocupou, portanto, em incluir de forma cuidadosa a pesquisadora na análise de dados, tendo em vista que ela pertence ao mesmo grupo que os participantes: psicólogos residentes em Saúde da Mulher do HESFA/UFRJ. Compartilhar com eles certo fundo de experiências que a residência proporciona, além do fato de ela ser da mesma categoria profissional, permitiu-lhe vivenciar um contexto de aproximação que não pôde ser ignorado. Assim, essa escolha ativa trouxe para pesquisa tanto sua história própria de pesquisadora como seu engajamento repleto de afetos. Por outro lado, o reconhecimento desta dimensão não significa que ela assumiu um papel privilegiado na pesquisa, mas sim que ela posicionou todos os atores envolvidos, pesquisadora e participantes, num mesmo plano horizontal, com a valorização de todas as vozes.

\section{Resultados e discussão}

Aos participantes de cada grupo focal foram entregues, antes de sua realização, o Termo de Consentimento Livre e Esclarecido (TCLE) e um pequeno formulário. Neste último, perguntou-se sobre: sexo, idade, instituição da graduação em psicologia, município da instituição da graduação, ano de conclusão do curso, atual situação na residência (R1, R2 ou formado) e sobre outras experiências profissionais como psicólogo.

Observando os dados coletados pelos formulários, tem-se que, do total de dez participantes da pesquisa, nove são do sexo feminino e um do masculino, com idades que variam entre 25 e 31 anos. Quanto à graduação em psicologia, as instituições públicas foram citadas por sete residentes, enquanto as particulares, por três deles. Houve apenas uma instituição situada fora do município do Rio de Janeiro mencionada, onde se formaram três psicólogos(as). Já o ano de conclusão de curso dos residentes variou entre 2010 e 2017. Acerca de "outras experiências profissionais como psicólogo", foram citados estágios em psicologia clínica, psicologia do trabalho, psicologia hospitalar, recursos humanos, mediação escolar e atuação em pesquisa acadêmica.

A fim de assegurar neutralidade e sigilo na nomeação dos residentes e, ao mesmo tempo, conferir pessoalidade aos mesmos, a escolha dos nomes fictícios dos participantes correspondeu aos elementos contidos na imagem clássica do sistema solar: do Sol a Plutão. A partir da análise dos dados coletados por meio dos grupos focais, foram identificadas seis categorias.

\section{Expectativa inicial de cursar uma residência}

Logo no início do grupo focal, os participantes foram convidados a recordar o momento que antecedeu a escolha por uma RMS. Dessa forma, surgiram duas subcategorias: "Amparo institucional" e "Desconhecimento pairando a escolha".

\section{Amparo institucional}

Esta subcategoria abarca todos os aspectos positivos citados pelos residentes acerca da expectativa 
inicial de cursar uma residência. Devido, sobretudo, à insegurança para atuar enquanto psicólogo, a residência foi mencionada como um lugar que pudesse acolher o psicólogo ainda com pouca experiência profissional, dando lhe um respaldo institucional. A residência surgiria então como uma segurança almejada (e necessária) para se dar os primeiros passos rumo à entrada no mercado de trabalho, como uma iniciação profissional: "Eu ainda não me sentia preparada para ir para clínica ou prestar mestrado e eu entendia que a residência era uma mistura de estudo e trabalho" (Sol R1).

Muitas falas destacaram também a possibilidade, vista como vantagem, da residência reunir estudo e trabalho, teoria e prática, por ser ela uma especialização em serviço. Além disso, o retorno financeiro foi expresso em algumas falas como mais um ponto a favor da residência.

Por fim, as expectativas acerca da residência também abrangeram a especificidade do programa do HESFA: Saúde da Mulher. O interesse na temática foi apontado como um elemento importante na escolha que pode ter surgido ao longo da graduação ou, até mesmo, devido a uma afinidade pessoal com temas que envolvam mulheres e gênero.

\section{Desconhecimento pairando a escolha}

Como contraponto às expectativas positivas iniciais para cursar uma residência, apareceram também falas que retratam incertezas na escolha pela residência em razão do desconhecimento ou da falta de informações tanto em relação ao Programa de Residência Multiprofissional em Saúde da Mulher do HESFA/ UFRJ, quanto sobre o funcionamento de uma RMS, sobretudo a dúvida em torno do termo "multiprofissional" e das expectativas em torno de uma residência multiprofissional: "Eu não conseguia nem contextualizar o que seria o multi, não fazia ideia do que fosse aquilo" (Plutão Formado). Essas ilustrações talvez possam retratar como todo esse desconhecimento em torno das RMS ainda é reflexo de sua recente existência no Brasil.

\section{Graduação em psicologia: lacunas e contribuições}

Nessa categoria aparecem os aspectos da graduação que, na visão dos psicólogos residentes, funcionaram como facilitadores ou como lacunas para sua inserção no programa de Residência Multiprofissional em Saúde da Mulher. Desse conjunto mais amplo, emergiram três subcategorias: "Experiência com saúde da mulher na graduação", "O que faltou (ou não) na graduação", e “Tradição da Psicologia na área clínica”.

\section{Experiência com saúde da mulher na graduação}

Nos três grupos focais, alguns participantes trouxeram o contato com a temática da saúde da mulher durante a graduação, sobretudo nos últimos períodos em disciplinas eletivas e, principalmente, em pesquisas e estágios. Tal experiência ganhou voz tanto para justificar o processo de escolha pela residência em saúde da mulher, como para marcar uma possível lacuna ou contribuição da graduação nos estudos e práticas envolvendo questões de gênero, sexualidade, e atenção no cuidado às mulheres.

Aqueles que fizeram pesquisas e/ou estágios que abarcassem saúde da mulher viram na graduação a possibilidade de introdução da temática e, na residência, de seu aprofundamento. Mesmo com essas vivências, os residentes contaram como elas ocorreram dentro de um campo muito específico: em maternidades e no trabalho com mulheres em situação de violência. Por esta razão, ainda que a graduação em muitos casos tenha contribuído ao oferecer um horizonte em saúde da mulher, as oportunidades eram restritas a recortes específicos de mulheres e abordagens. Com isso, eles buscaram uma residência que talvez pudesse olhar para saúde da mulher num sentido mais abrangente.

\section{O que faltou (ou não) na graduação}

Diante da questão sobre quais aspectos da graduação contribuíram ou dificultaram a inserção na RMS, os residentes concordaram e complementaram as falas um do outro em muitos momentos.

Foi curioso observar que, por mais que tenham apontado contribuições da graduação, uma vez que ofereceu bases cruciais para formação, quase todos reconheceram lacunas sentidas ou percebidos com maior ênfase quando passaram a habitar o espaço institucional de uma RMS. Alguns participantes atribuíram às lacunas o fato de se formarem em instituições particulares, mas, ao longo do grupo focal e a partir do debate com residentes formados em universidades públicas, perceberam e concordaram que as lacunas retratam, na verdade, uma defasagem da formação em psicologia como um todo, sem necessariamente haver uma diferenciação marcada entre o ensino 
público e o particular. "Eu enxergo pontos facilitadores na minha chegada até aqui, mas eu gostaria de frisar uma lacuna em relação à formação do psicólogo para saúde pública" (Mercúrio R1).

Dentre as lacunas mais citadas, a carência de disciplinas na graduação voltadas para o trabalho em grupo e na área da saúde apareceu em destaque. A área de saúde da mulher, mais especificamente, e o estudo de questões de gênero também foram citados como um tópico pouco visto na graduação, o que tornou ainda mais imprescindível o aprofundamento destes conteúdos ao entrarem numa residência em saúde da mulher. "Acho que não tem espaço pra trabalhar em equipe na nossa graduação, realmente é o psicólogo com o psicólogo só" (Sol R1); "A gente tem matérias na área da saúde, acho que eletivas. Mas em saúde da mulher eu não lembro de nada" (Marte R2). Além disso, foi relatado que estes debates apareciam, sobretudo, em disciplinas eletivas ou optativas, o que demonstra ser possível o estudante se formar em psicologia sem ter tido um contato mais aprofundado com essas questões fundamentais.

Toda essa falta exigiu um esforço redobrado do recém-formado ao entrar na residência de estudar e conhecer conceitos em saúde pública enquanto se depara com todas as dificuldades que pairam o trabalho em equipe multiprofissional. Não dava mais para pensar nem trabalhar isolado ou só entre psicólogos. Era preciso se adaptar, expandir o olhar e qualquer caixinha trazida da graduação.

Neste sentido, a fim de dar conta desta lacuna, Ceccim e Feuerwerker (2004, citado por Hüning, Silva, Silva e Lessa, 2013) propõem que "a Integralidade deve ser um eixo norteador de mudanças na graduação das profissões de saúde, por promover ações de atenção à proposta política do SUS, sustentando-se através da articulação com as redes" (p. 163). Considerando-se a psicologia como uma das profissões de saúde, a integralidade se torna fundamental para qualificar a formação do psicólogo tendo em vista sua futura atuação em equipes multiprofissionais.

\section{Tradição da psicologia na área clínica}

Os residentes concordaram sobre a hipótese de a formação em psicologia ainda se ancorar no modelo tradicional, que coloca a clínica como destaque teórico e almejo prático. Tal lacuna na formação prejudica o (re)conhecimento de outras possibilidades de atuação, como a área da saúde. Desse modo, foi citado como, ao chegar à RMS, tornou-se mais urgente na formação em psicologia a presença de estudos que envolvam as políticas da saúde pública.

Segundo Hüning et al. (2013), o currículo é atravessado por questões socioculturais, o que o faz priorizar certos conteúdos, deixando outros em segundo plano. Já Batista, Carmona e Fonseca (2014) afirmam a necessidade de maior integração entre os campos de ensino e prática, assim como a construção de currículos que reflitam de fato as necessidades da população de modo contextualizado.

Apesar das lacunas na graduação, Guareschi, Machry, Reis, Dhein e Bennemann (2012) alegam ter havido mudanças na formação em psicologia nos últimos anos, sobretudo, com vistas à atuação profissional nos serviços de saúde. Desse modo, parece haver um deslocamento gradual da formação para uma psicologia em maior consonância com os princípios do SUS.

A clínica também vem, ao longo das décadas, se (re)inventando, se tornando mais ampla e plural, expandindo o setting terapêutico e alcançando novos horizontes, inclusive na área da saúde.

\section{Desafios na residência}

Acerca das surpresas e dificuldades na residência, foram relatados, sobretudo, desafios. É interessante notar como alguns incômodos pareciam se referir exatamente ao momento na residência em que os psicólogos estavam. Por exemplo, algum desconforto no grupo focal com R1 poderia não ser mais uma questão para os R2 ou formados. O que antes era sentido como um problema, poderia agora ser (re)significado como uma experiência válida em meio às dificuldades, um aprendizado e, talvez, uma nova maneira de atuar profissionalmente. Assim, surgiram quatro subcategorias: "Relação residente-instituição", "O psicólogo que observa", "Identidade de psicólogo", e "Lidando com o real”.

\section{Relação residente-instituição}

Esta subcategoria apareceu na contramão de tudo o que foi dito, em um momento anterior, sobre as vantagens da residência como amparo institucional. Ou seja, ela enfatiza que, por mais que houvesse uma expectativa inicial de respaldo da instituição enquanto um lugar protegido e seguro, na prática, isto se tornou um grande desafio para os residentes. A relação residente-instituição ganha forma de obstáculo ao oferecer tutela e ao determinar regras e padrões de 
trabalho na inserção do residente. Os participantes reclamaram ainda de como as relações institucionais, por vezes, eram marcadas por relações de poder percebidas como autoritárias e inflexíveis, e como havia pouca abertura para críticas e sugestões nos diferentes espaços da residência.

Embora esta subcategoria tenha sido colocada de forma mais enfática no grupo focal de R1, o que talvez expresse também uma dificuldade de adaptação no começo da residência, ela também chegou a ser debatida nos demais grupos: "Eu senti muita dificuldade de dialogar com outros profissionais, de propor espaços que pudessem ser discutidos casos e outras questões inerentes ao processo de trabalho" (Saturno R2).

\section{O psicólogo que observa}

Antes de entrar na questão da observação, é preciso minimamente contextualizar o modelo de trabalho no programa da Residência Multiprofissional em Saúde da Mulher do HESFA/UFRJ. No primeiro ano da residência, há uma ambientação do residente e sua aproximação com o trabalho multiprofissional a partir dos trios que trabalham sempre juntos. É um período de maior amparo institucional, o que tem seu lado positivo e outro, negativo. Neste momento, muitas vezes o residente ainda não pode atuar diretamente ou sozinho, sendo colocado no papel de observador, ainda que isto não restrinja suas possibilidades. Já no segundo ano, os trios são desfeitos e cada profissional trabalha de modo mais independente e autônomo, com um olhar mais ampliado graças à experiência com o trabalho multiprofissional.

Por ser um incômodo que se refere a um momento específico da residência, esta subcategoria surgiu apenas no grupo focal com residentes do primeiro ano, como a frustração relatada pelo psicólogo R1 de ficar no lugar de observador nos atendimentos e outras atividades: "A gente fica naquela ânsia de poder atender, de querer atuar. Ficar só observando é muito rico também, mas realmente. .." (Vênus R1). Talvez pelos residentes do segundo ano e os formados já estarem distantes dessa vivência de observação, esta não foi trazida em seus grupos, o que poderia apontar para uma possível superação de um obstáculo não mais encarado como dificuldade, mas sim como potência.

\section{Identidade de psicólogo}

Outro ponto amplamente debatido nos grupos focais foi o desafio de se encontrar numa RMS, de adquirir uma identidade profissional enquanto psicólogo ao atuar nas equipes multiprofissionais e nos espaços institucionais. Esta questão talvez fale bastante do momento inicial da residência, em que o papel do psicólogo na saúde e no programa de residência se torna uma dúvida angustiante.

Os residentes comentaram como inicialmente não se reconheciam na identidade de profissional de saúde, tendo a sensação de que as particularidades de sua profissão poderiam ser apagadas caso o trabalho multiprofissional afrouxasse os limites de cada categoria profissional: "Quando R1 eu pensava 'estou deixando de ser psicóloga', por achar que psicologia era só atendimento clínico. E com essa angústia me distanciando da psicologia e me aproximando de uma coisa que eu não sabia o que era" (Júpiter R2)

Por essa razão, essa subcategoria também foi mais expressiva no grupo R1. Os residentes do segundo ano e os formados também citaram seus incômodos nessa (re)descoberta por uma identidade, mas, na maioria das vezes, fazendo referência ao passado, recordando como se sentiram nos primeiros meses da residência. Parece, com isso, ter ocorrido um amadurecimento no processo de dar sentido à identidade de psicólogo, que aos poucos agregou também algumas ramificações, como a identidade de profissional de saúde. "Porque antes eu achava que existia um limite muito delimitado, mas têm coisas que são básicas e, enquanto profissional de saúde, eu considero que deva saber" (Júpiter R2). Se reconhecer com uma identidade, com todas suas nuances, pode conferir, por fim, uma maior segurança para atuar e para se posicionar frente ao trabalho em uma equipe multiprofissionais.

Ainda sobre as dificuldades e descobertas em torno da identidade do psicólogo, um(a) participante afirmou que a vivência na residência lhe fez "pensar em outras formas de fazer psicologia” (Mercúrio R1) e se deparar com um deslocamento crucial: a identidade do psicólogo do e para o SUS que lida com as necessidades e demandas da população que faz uso de seus serviços.

A principal crítica veio no bojo dessa dificuldade, tanto do psicólogo quanto dos outros integrantes de uma equipe, em enxergar a saúde como campo de atuação do psicólogo, em saber o que o psicólogo faz ou poderia fazer lá. Ainda em meio a ela, foi trazida a urgência do psicólogo de se fazer presente na saúde e no trabalho multiprofissonal, em (re) afirmar o seu papel e lugar, em se colocar, em agir: 
Quando a psicologia vai parar de engatinhar? Porque é muito fácil falar que o hospital é o lugar do médico. Mas a gente tem que chegar e falar: então, a gente está trazendo a nossa mala, o nosso cobertor e o nosso travesseiro. Eu quero ocupar essa casa! (Urano Formado).

\section{Lidando com o real}

A última subcategoria acerca dos desafios na residência traz a constatação de como o trabalho na residência se dá ou se deu na prática, marcando até que ponto o prescrito se aproxima ou se afasta do real. Os participantes destacaram como dificuldade a falta de espaços para trabalhar a multidisciplinaridade. Isto quer dizer que, apesar da proposta de uma RMS falar de integralidade, abertura para o diálogo e trocas entre diferentes saberes, os residentes se depararam no dia a dia com espaços e pessoas que não faziam valer o que era dito ou suposto: "Uma das questões que pra mim foi desafiante é perceber como equipes não trabalham multi nem um pouco" (Netuno Formado). Assim, eles se depararam com a necessidade de pensar em como abrir brechas nos setores, em como construir um diálogo com equipes, em como trabalhar e resistir a essa realidade.

Ainda na direção do confronto entre expectativa e realidade, os residentes trouxeram uma questão preocupante a nível macro: o desmonte do SUS. O cenário político atual está marcado por uma série de retrocessos nas políticas públicas e por cortes do governo na área da saúde. Este fato ameaça direitos constitucionais, tornando mais precária a oferta de serviços, restringindo atendimentos e procedimentos e ameaçando o cuidado integral à saúde de milhões de brasileiros. "Porque não dá, não tem infraestrutura, não tem o mínimo pra você fazer acontecer. E isso gera sofrimento pro trabalhador" (Netuno Formado). Isso tudo atinge ainda o próprio propósito da residência de capacitar profissionais para trabalharem no SUS futuramente, uma vez que a sustentação e continuidade dos programas de residência, assim como do SUS, se veem ameaçadas. Diante dessa triste conjuntura, não há qualquer garantia de que o profissional possa trabalhar no SUS após a residência.

\section{Trabalho multiprofissional}

Em se tratando de uma RMS, havia a expectativa de que o trabalho multiprofissional surgisse como temática central em todos os grupos focais. Esta categoria acabou dividida em duas outras subcategorias: "Atuação em trios multiprofissionais" e "Dificuldades e contribuições".

\section{Atuação em trios multiprofissionais}

Para alguns participantes, o termo "multiprofissional" significava, a princípio, apenas que naquele espaço teria profissionais de formações diferentes. Com isso, a expectativa ainda era de um trabalho mais compartimentado, sem tanta interação entre os saberes. Isso talvez expresse uma confusão comum sobre o que é o trabalho multiprofissional, sobre o que é integrar e trabalhar junto. Mais uma compreensão e vivência que apenas a trajetória pela residência poderia demostrar.

Apesar da estranheza inicial relatada pelos participantes do grupo R1, frequentemente acompanhada por certo desconforto, os residentes dos demais grupos focais discursaram mais uma vez sobre ter havido uma mudança em sua percepção. Parecia que, somente após passar pelo convívio com os trios multiprofissionais, essa experiência poderia ganhar novos contornos e significados. Somente após ela ser conhecida na prática é que poderia ser valorizada. À medida que o contato multiprofissional promovia reflexões e ensinamentos, ele também transformava e era transformado por cada integrante do trio: "Como Rl eu não tinha a dimensão do quanto isso era importante. Mas como R2 eu não consigo mais fazer um atendimento não levando em consideração aspectos que aprendi com meu trio" (Júpiter R2).

Parece então que o trabalho multiprofissional permitiu uma qualificação na escuta e atendimento ao usuário, permitindo olhá-lo de forma integral como um ser biopsicossocial. Essa compreensão se faz necessária para se (re)pensar a atenção à saúde preconizada pelo SUS na medida em que ela se pauta pelo princípio da integralidade. A integralidade exige, assim como o trabalho multiprofissional, uma dissolução de barreiras entre as categorias profissionais e um "rompimento das fronteiras identitárias dos seus objetos de estudo" (Guareschi et al., 2012, p. 511). A atuação em trios multiprofissionais foi relatada, portanto, como um meio que proporcionou maior flexibilidade na atuação, assim como abertura para o diálogo e reconhecimento da relevância de aspectos que, até então, ficavam à margem. 


\section{Dificuldades e contribuições}

No que se refere ao trabalho multiprofissional na residência - para além dos trios compostos por residentes - os grupos focais relataram tanto contribuições quanto dificuldades que a atuação proporciona ou já proporcionou: "Eu acho que agregou muito, porque eu consegui aprender um pouco do outro, o outro aprender comigo. Está sendo até melhor do que eu imaginava, e acho que quando terminar vou sentir falta" (Vênus R1).

Em meio às dificuldades no trabalho em equipe, destacam-se as falas dos participantes sobre aquelas referentes ao contato com formações profissionais diferentes que, talvez por conta das especificidades de sua graduação e campo do saber, por vezes prejudicavam a troca, a integração E a escuta do outro: "A gente vem de um lugar que é do indivíduo. E, quando você vai dialogar com alguém do serviço social, ela está vendo o macro. Então são duas pessoas falando coisas com uma visão muito diferente" (Plutão Formado). Ou seja, a residência parece exigir um esforço em lidar com todas as barreiras que o trabalho em equipe multiprofissional impõe.

\section{0 papel do residente e da residência para o SUS}

A questão levantada sobre o papel do residente para a residência e desta para o SUS gerou suspiros, trocas de olhares, minutos de silêncio e uma constatação de um (a) participante: "que pergunta difícill?. Para essa categoria, surgiram outras quatro subcategorias: "Promover reflexões e mudanças", "Processo em construção permanente", "Lugar difícil do residente" e "Criar pontes".

\section{Promover reflexões e mudanças}

Esta subcategoria é construída em torno de um papel do profissional que se constrói no presente mas que visa um futuro. Promover reflexões e mudanças fala do desenvolvimento de uma formação mais crítica por parte dos residentes e da possibilidade de levar sua reflexão, crítica ou sugestão para os lugares por onde passa. Fala, sobretudo, do papel do residente em estudar e rever a prática, em levar para os outros profissionais da equipe um olhar ampliado e, de fato, multiprofissional. Isso tudo se concretiza no papel árduo e potente de deixar uma marca da sua contribuição para os setores e equipes, "um legado para a instituição" (Terra R1).
Esse papel também vai ao encontro da seguinte ideia: "O meu papel como residente foi mais de dar gás novo ... de dar um novo olhar" (Urano Formado). Dito de outra forma, se o residente pode mudar a instituição, a residência, por sua vez, pode impactar a realidade do SUS.

\section{Processo em construção permanente}

Pela própria residência ser um processo que, ao longo de dois anos, soma desafios e aprendizados, o papel do residente também foi citado como algo que não é fechado, mas sim como um processo que continua permanentemente. Essa categoria fala, portanto, daquilo que não está dado e que se constrói no dia a dia, precisando ser, a todo tempo, (re)investido e (re)inventado.

\section{Lugar difícil do residente}

A dificuldade em ocupar e exercer o papel de residente surgiu, sobretudo, no grupo focal R1. Dificuldade pela quantidade e intensidade de trabalho, pelo desgaste, que vai além do físico e atravessa os muros da instituição, por uma invisibilidade que pede reconhecimento, por "um trabalho mental que é pesado" (Mercúrio R1). Tal dificuldade talvez não tenha aparecido nos demais grupos devido à adaptação que seus participantes tiveram ao longo de suas travessias.

\section{Criar pontes}

Por fim, emergiu esta subcategoria, que trata do papel de integração do residente dentro e entre as equipes e instituições e de sua capacidade de criar laços, de formar redes. Esse tópico condiz com o princípio da integralidade do SUS, em que deve haver garantia de que o cuidado ao usuário será integrado entre os diferentes níveis de atenção em saúde e, inclusive, entre diferentes setores, segundo a necessidade. Criar pontes assume relevância, portanto, no serviço e no dia a dia da instituição, à medida que busca atender à integralidade e à intersetorialidade preconizadas pelo SUS.

\section{Residência como divisor de águas}

A última categoria da pesquisa retrata o que a vivência em uma RMS pode proporcionar para seus profissionais em formação. Nesse sentido, muitos relatos expuseram ricos aprendizados, desafios e até 
expectativas positivas sobre o pós-residência. Talvez essa categoria ajude a responder de que forma o psicólogo residente pode ser enriquecido pela experiência da residência para a sua formação, isto é, de que forma o vivido pode adquirir contornos antes não imaginados: "A surpresa positiva de como eu mudei! Como eu consegui alcançar outro nível de entendimento da psicologia. Que eu posso sair muito da minha caixinha formada ali" (Urano Formado).

Dentre os aprendizados trazidos pelos participantes, um deles se refere a discussões teóricas sobre saúde da mulher, princípios do SUS, direitos dos usuários e políticas públicas. Isso tudo foi relatado como um crescimento adquirido na residência, como aquilo que proporcionou "mudanças de paradigma".

A partir da bagagem profissional, outros aprendizados se referiram à descoberta dos limites do psicólogo em sua atuação e da compreensão de seu papel e lugar. Descoberta feita a partir da experimentação e do estranhamento, descoberta até mesmo do que "não fazer": "E o fato de aprender o que não fazer contribuiu muito também e de estar aberta a aprender com o que é possivel" (Júpiter R2). Com isso, a insegurança inicial, razão de busca por um amparo institucional, parece ser substituída por uma maior segurança para a prática tanto dentro quanto fora da residência. Esses aspectos podem ser corroborados pelo estudo de Lima e Santos (2012) com psicólogas residentes, que demonstra como a experiência em uma residência multiprofissional contribui no aprendizado das habilidades de negociação para lidar com hierarquias no processo de trabalho, maior tolerância e diálogo, questionamento constante de suas práticas, atitudes transdisciplinares e maturidade profissional para exercício de um cuidado mais qualificado e resolutivo em saúde.

O próximo extrato ilustra muito bem a essência da residência como divisor de águas: "A gente fica muito mais crítico. Eu vejo uma mulher grávida e não fico preocupado(a) com a criança unicamente. A primeira coisa que pergunto é como a mulher está" (Urano Formado). Esse trecho fala de como os estudos e práticas da residência instigam um senso crítico que cada vez mais problematiza questões despercebidas em nossa cultura e sociedade, como o lugar da mulher.

\section{Considerações finais}

Tendo em vista os objetos da pesquisa, pode-se observar que, em relação à percepção do psicólogo residente acerca do seu papel na Residência Multiprofissional em Saúde da Mulher do HESFA/UFRJ e da contribuição desta para sua formação, foram identificados tanto dificuldades, quanto aprendizados. Os resultados da pesquisa apontam que o amparo institucional da residência se coloca tanto como uma expectativa segura após a graduação, quanto como um desafio para a atuação do psicólogo, assim como evidenciam lacunas e contribuições na graduação em psicologia e indicam a necessidade de maior inclusão de temáticas de grupo, saúde e gênero nas grades curriculares. Além disso, a pesquisa registra as frustrações do residente ao lidar com o contexto atual de sucateamento do Sistema Único de Saúde; a importância do trabalho multiprofissional para garantir atenção integral em saúde; e os aprendizados que fazem da passagem pela residência um divisor de águas.

Em relação à análise de possíveis diferenças na percepção do psicólogo residente dependendo do período na residência em que se encontra, verificou-se que há de fato nuances que denotam a singularidade do acúmulo de experiências vividas. É necessário reconhecer que, em muitos aspectos, residentes do primeiro ano, do segundo e os formados concordaram, como nas questões sobre a expectativa inicial de cursar uma residência, sobre os papéis reconhecidos por eles na instituição e em equipes multiprofissionais e sobre a identificação de lacunas advindas de sua formação em psicologia. Entretanto, outros pontos mostraram uma mudança nos sentidos atribuídos pelos residentes ao longo de suas trajetórias. O que antes era angustiante e desafiador, pode ser reconhecido como indispensável ou relevante para um crescimento pessoal e profissional, (re)pensado e (re)significado com novos contornos aliados à prática. $\mathrm{O}$ aprendizado obtido durante a residência pode, portanto, impulsionar caminhos cada vez mais potentes e possíveis.

O processo de pesquisar levando-se em conta o papel da pesquisadora, que também é psicóloga residente, em todas as etapas desse estudo, requisitou um trabalho cuidadoso, ao mesmo tempo em que permitiu uma abertura e uma maior disponibilidade para problematizar todas as afetações envolvidas no encontro com os residentes, assim como dados, lembranças, percepções, sentimentos etc. Todos esses achados permitem afirmar que espaços como a residência multiprofissional em saúde constituem campos teórico-práticos de amadurecimento profissional do psicólogo profissional de saúde. 


\section{Referências}

Batista, C. B., Carmona, D. S., \& Fonseca, S. L. (2014). Formação em saúde e os cenários de aprendizagem no curso de psicologia. Psicologia Argumento, 32(7), 17-25. http://dx.doi.org/10.7213/psicol.argum.32.078.DS02

Bardin, L. (1977). Análise de conteúdo. Edições 70.

Benevides, R. (2005). A Psicologia e o Sistema único de Saúde: Quais interfaces? Psicologia \& Sociedade, 17(2), 21-25. https://doi.org/10.1590/S0102-71822005000200004

Conselho Nacional de Educação. (2001). Projeto de resolução institui as diretrizes curriculares nacionais para os cursos de graduação em psicologia. Ministério da Educação e Cultura.

Conselho Nacional de Educação (2004). Projeto de resolução institui as diretrizes curriculares nacionais para os cursos de graduação em psicologia. Ministério da Educação e Cultura.

Constituição da República Federativa do Brasil de 1988. (1988). Senado Federal.

Guareschi, N. M. F., Machry, D. S., Reis, C., Dhein, G., \& Bennemann, T. (2012). Implicações da Área das Biomédicas na formação do psicólogo para o SUS. Psicologia Argumento, 30(70), 503-513. http://dx.doi.org/10.7213/psicol.argum.6137

Hüning, S. M., Silva, A. K., Silva, W. V. N., \& Lessa, F. M. S. (2013). Formação para o SUS nos cursos de psicologia em Alagoas. Psicologia em Estudo, 18(1). https:// doi.org/10.1590/S1413-73722013000100016

Lei $n^{\circ} 11.129$, de 30 de Junho de 2005. (2005). Institui o Programa Nacional de Inclusão de Jovens - ProJovem; cria o Conselho Nacional da Juventude - CNJ e a Secretaria Nacional de Juventude; altera as Leis nos 10.683, de 28 de maio de 2003, e 10.429, de 24 de abril de 2002; e dá outras providências. Presidência da República.

Lima, M., \& Santos, L. (2012). Formação de Psicólogos em Residência Multiprofissional: Transdisciplinaridade, Núcleo Profissional e Saúde Mental. Psicologia: Ciência e Profissão, 32(1), 126-141. https://doi.org/10.1590/ S1414-98932012000100010

Martins, G. M., Caregnato, R. C. A., Barroso, V. L. M., \& Ribas, D. C. P. (2016). Implementação de residência multiprofissional em saúde de uma universidade federal: trajetória histórica. Revista Gaúcha de Enfermagem, 37(3), Artigo e57046. http://dx.doi.org/10.1590/1983-1447.2016.03.57046

Pires, A. C. T., \& Braga, T. M. S. (2008). O psicólogo na saúde pública: formação e inserção profissional. Temas em Psicologia, 17(1), 151-162.

Ramos, A. S., Búrigo, A. C., Carneiro, C., Duarte, C. C., Kreutz, J. A., \& Ruela, H. C. G. (2006). Residências em Saúde: encontros multiprofissionais, sentidos multidimensionais. In Departamento de Gestão da Educação na Saúde, Residência multiprofissional em saúde: experiências, avanços e desafios (pp. 375-390). Ministério da Saúde, Secretaria de Gestão do Trabalho e da Educação na Saúde.

Santos, K. L., Quintanilha, B. C., \& Dalbello-Araujo, M. (2010). A atuação do psicólogo na promoção da saúde. Psicologia: Teoria e Pesquisa, 12(1), 181-196.

Secretaria de Atenção à Saúde (2010). Política Nacional de Humanização da Saúde: documento Base (4a ed.). Ministério da Saúde.

Tonetto, A. M., \& Gomes, W. B. (2007). A prática do psicólogo hospitalar em equipe multidisciplinar. Estudos de Psicologia, 24(1), 89-98. https://doi.org/10.1590/S0103-166X2007000100010

Virgínio, N. A., \& Nóbrega, M. M. L. (2012). Técnica de grupo focal: caracterizando a estratégia. Revista de Ciências da Saúde Nova Esperança, 10(1), 75-82. https://doi.org/10.17695/revnevol10n1p76\%20-\%2083

Isabel Sampaio dos Santos Ferreira

Especialista em Saúde da Mulher da Universidade Federal do Rio de Janeiro (UFRJ), Rio de Janeiro - RJ. Brasil.

E-mail: bel.ssf@gmail.com

(1) https://orcid.org/0000-0001-8864-7551 


\section{Cecília Teixeira Soares}

Doutora em Psicologia da Universidade Federal do Rio de Janeiro (UFRJ), Rio de Janeiro - RJ. Brasil.

E-mail: cecilia.tsoares@gmail.com

(10) https://orcid.org/0000-0003-2213-3376

Agradecemos ao HESFA e ao Programa de Residência Multiprofissional em Saúde da Mulher pela oportunidade de desenvolver esta pesquisa e, sobretudo, pela possibilidade de ampliar o olhar da psicologia na interface com diálogos multiprofissionais. Agradecemos também aos participantes da pesquisa pela disponibilidade em se permitirem afetar e serem afetados pelos encontros.

Endereço para envio de correspondência:

Instituto de Atenção à Saúde São Francisco de Assis (HESFA/UFRJ). Avenida Presidente Vargas, 2863, Centro. CEP: 20210-030. Rio de Janeiro - RJ. Brasil.

Recebido 28/01/2019

Aceito 13/01/2020

Received $01 / 28 / 2019$

Approved 01/13/2020

Recibido 28/01/2019

Aceptado 13/01/2020

Como citar: Ferreira, I. S. S., \& Soares, C. T. (2021). Residência multiprofissional em saúde e formação de psicólogos para o SUS. Psicologia: Ciência e Profissão, 41, 1-14. https://doi.org/10.1590/1982-3703003219139

How to cite: Ferreira, I. S. S., \& Soares, C. T. (2021). Multiprofessional residency in health and training of psychologists for the SUS. Psicologia: Ciência e Profissão, 41, 1-14. https://doi.org/10.1590/1982-3703003219139

Cómo citar: Ferreira, I. S. S., \& Soares, C. T. (2021). Residencia multiprofesional en salud y formación de psicólogos para el SUS. Psicologia: Ciência e Profissão, 41, 1-14. https:// doi.org/10.1590/1982-3703003219139 